\title{
O Direito Humano à Água e a Regulação do Saneamento Básico no Brasil: Tarifa Social e Acessibilidade Econômica
}

\author{
http://dx.doi.org/10.21527/2237-6453.2020.54.123-142
}

Recebido em: 22/6/2020

Aceito em: 20/11/2020

Camila Antonieta Silva Reis ${ }^{1}$, Ricardo Carneiro ${ }^{2}$

\begin{abstract}
RESUMO
O acesso à água potável e ao esgotamento sanitário é notoriamente reconhecido como uma condição essencial à proteção da saúde e à preservação da vida, tendo sido definido, por resolução da Organização das Nações Unidas (ONU), de 2010, como direito humano essencial. Essa essencialidade ganha contornos particularmente nítidos no atual contexto marcado pela pandemia da Covid-19. Para a promoção de objetivos sociais e econômicos relacionados à provisão dos referidos serviços, o marco regulatório do setor de saneamento básico brasileiro introduziu a necessidade de instituição de agências independentes com a atribuição de disciplinar e fiscalizar as atividades das empresas atuantes na área. Dentre os diversos desafios postos à atividade reguladora, ressalta-se a dificuldade de acesso, pela população de baixa renda, aos serviços setoriais. Um dos instrumentos usualmente empregados para oportunizar esse acesso é a denominada Tarifa Social. Nesse contexto, o artigo busca traçar uma visão panorâmica de sua utilização, em âmbito nacional, na prestação dos serviços setoriais, utilizando-se de dados do Sistema Nacional de Informações sobre Saneamento - SNIS. Verificou-se que o instrumento se faz presente na maior parte dos municípios, constatando-se, entretanto, grande heterogeneidade nos critérios adotados para sua concessão que, muitas vezes, se dissociam do principal objetivo de sua instituição.
\end{abstract}

Palavras-chave: Regulação. Saneamento. Tarifa social.

\section{THE HUMAN RIGHT TO WATER AND THE REGULATION OF BASIC SANITATION IN BRAZIL:} SOCIAL TARIFF AND ECONOMIC ACCESSIBILITY

\begin{abstract}
Access to drinking water and sanitation is notoriously recognized as an essential condition for the protection of health and the preservation of life, having been defined, by the United Nations (UN) resolution of 2010, as an essential human right. This essentiality gains particularly clear contours in the current context, marked by the Covid-19 pandemic. For the promotion of social and economic objectives related to the provision of these services, the regulatory framework of the Brazilian basic sanitation sector introduced the need for the establishment of independent agencies with the attribution of disciplining and supervising the activities of companies operating in the area. Among the various challenges posed to regulatory activity, the difficulty of access, by the low-income population, to sector services is highlighted. One of the instruments usually used to provide this access is called the Social Tariff. In this context, the article seeks to draw a panoramic view of its use, at the national level, in the provision of sectorial services, using data from the National Sanitation Information System - SNIS. It was found that the instrument is present in most municipalities, noting, however, great heterogeneity in the criteria adopted for its concession, which are often dissociated from the main objective of their institution.
\end{abstract}

Keywords: Regulation. Sanitation. Social Tariff.

\footnotetext{
${ }^{1}$ Autora correspondente. Agência Reguladora de Serviços de Abastecimento de Água e de Esgotamento Sanitário do Estado de Minas Gerais - Arsae-MG. Rodovia Papa João Paulo II, 4001, 5o andar - Cidade Administrativa - Serra Verde. CEP 31630-901. Belo Horizonte/MG, Brasil. http://lattes.cnpq.br/1024593165193429. http://orcid.org/0000-0001-7830-9866 camilaasreis@yahoo.com.br

2 Fundação João Pinheiro (FJP). Belo Horizonte/MG, Brasil.
} 
O fornecimento apropriado de saneamento básico é notoriamente reconhecido como uma condição essencial à proteção da saúde e à preservação da vida. Sua universalização em escala global é considerada um dos mais relevantes desafios do século 21, o que adquire particular relevância no cenário atual marcado pela pandemia da Covid-19.

A relevância do tema foi reconhecida pela Assembleia Geral da Organização das Nações Unidas (ONU), que, por meio da aprovação da Resolução A/RES/64/292, em 2010, considerou "o direito à água potável e limpa e ao saneamento como um direito humano essencial para o pleno gozo da vida e de todos os direitos humanos". O texto da resolução explicita a enorme preocupação com a situação do saneamento à época: em escala global, aproximadamente 884 milhões de pessoas não tinham acesso à água limpa e mais de 2,6 bilhões não dispunham de saneamento básico. Estudos adicionais demonstraram que, anualmente, aproximadamente 1,5 milhões de crianças menores de cinco anos falecem em decorrência da precariedade dos serviços de saneamento básico (ONU, 2010a).

Ainda em 2010, a Resolução n. 15/9, do Conselho dos Direitos Humanos da ONU, ratificou o status de direito humano ao acesso à água potável, atribuindo aos Estados a obrigatoriedade de provê-la a toda população (ONU, 2010b). Adicionalmente, a resolução reafirmou a necessidade de aprovação e estabelecimento de marcos regulatórios efetivos para os provedores dos referidos serviços, além de destacar a necessidade de o Estado viabilizar a atuação de instituições reguladoras públicas para aplicação e fiscalização destas normas (ONU, 2010b).

No Brasil, a atual estrutura institucional do setor tem, como fundamentos, a Lei Federal n. 11.445/07, denominada Lei de Diretrizes Nacionais para o Saneamento Básico (LDNSB), seu Decreto Federal regulamentador n. 7.217/10 e o Plano Nacional de Saneamento Básico (Plansab), aprovado em 2014. O referido arcabouço legal apresenta uma série de normas relacionadas ao exercício da titularidade, planejamento, regulação e gestão dos serviços de abastecimento de água e esgotamento sanitário. Cumpre destacar que a regulação e a fiscalização por parte do poder público passaram a ser requeridas formalmente somente após a promulgação da Lei n. 11.445/07, que determinou a obrigatoriedade de instituição de agências reguladoras com tal finalidade.

A LDNSB apresenta importantes dispositivos que associam o acesso à água a um direito social universal. A diminuição das desigualdades regionais, a promoção da saúde pública, a criação de empregos e de renda, a contribuição para o desenvolvimento do país e a inclusão social, são alguns dos objetivos da política setorial. A referida lei também prevê a publicação, por entidade reguladora, de regras relacionadas aos fatores econômico, técnico e social da prestação dos serviços, o que inclui aspectos relativos a estruturas tarifárias e subsídios tarifários e não tarifários, os quais são considerados instrumentos econômicos de política social para viabilizar a universalização do acesso aos serviços, principalmente para localidades e populações de baixa renda (BRASIL, 2007).

Umas das diretrizes estipuladas pela LDNSB para a determinação do sistema tarifário é a ampliação do acesso dos cidadãos de baixa renda ao serviço. Ao afirmar, entretanto, que "poderão ser adotados subsídios tarifários e não tarifários para os usuários que não tenham capacidade de pagamento suficiente para cobrir o custo integral dos serviços" (BRASIL, 2007, artigo 29, § 20), a lei não é clara quanto aos critérios que de- 
vem ser utilizados para o alcance desse objetivo. Responsável pela determinação de tarifas que assegurem a modicidade tarifária, cabe à regulação, portanto, um papel protagonista na viabilização do acesso aos serviços pela população economicamente vulnerável. Um dos instrumentos tarifários usualmente empregados para oportunizar a inclusão social no acesso aos serviços públicos essenciais, como o saneamento básico, é a denominada Tarifa Social, que atribui uma tarifa reduzida à população economicamente vulnerável.

A partir da perspectiva de uma gestão socialmente justa das atividades de abastecimento de água e esgotamento sanitário, o artigo tem por objetivo promover uma discussão sobre estruturas tarifárias inclusivas voltadas a viabilizar o acesso aos serviços de saneamento básico pela população economicamente vulnerável, traçando um panorama da aplicação da Tarifa Social pelas empresas concessionárias atuantes na área em âmbito nacional. Para a consecução do objetivo proposto, a análise desdobra-se em cinco seções, além desta introdução e das conclusões. A segunda seção é dedicada a uma breve discussão teórica acerca da noção de regulação e das motivações econômicas e sociais que fundamentam sua adoção. Na terceira seção direciona-se a atenção para a abordagem da necessidade da regulação no setor, destacando, dentre os instrumentos regulatórios, a política tarifária, na qual se inscreve a Tarifa Social. A quarta seção dedica-se ao exame da política tarifária setorial. A quinta seção descreve a metodologia utilizada na avaliação do nível de adoção da Tarifa Social pelas prestadoras do serviço. Na sexta seção examina-se a adoção da Tarifa Social na prestação dos serviços de saneamento básico no território nacional, incluindo os critérios utilizados com tal finalidade por parte das empresas concessionárias estaduais a partir de dados do Sistema Nacional de Informações sobre Saneamento - SNIS - referentes a 2018. A análise empreendida fundamenta-se em revisão bibliográfica e documental, além das informações disponibilizadas pelo SNIS.

Ressalta-se, por relevante, que ao se avaliar a aplicação da Tarifa Social parte-se do pressuposto de que os potenciais usuários já possuam acessibilidade às redes fisicamente instituídas de abastecimento de água e esgotamento sanitário, o que não abrange, portanto, a parcela da população para a qual os serviços ainda não estão disponíveis por limitação da extensão das referidas redes. Nesse sentido, a análise concentrou-se na perspectiva de utilização do subsídio cruzado como instrumento para assegurar a acessibilidade econômica aos usuários de baixa renda, e não na perspectiva de viabilização de investimentos com vistas à universalização dos serviços.

\section{REGULAÇÃO: CONCEITOS, ABRANGÊNCIA E APLICAÇÃO}

A crescente difusão do neoliberalismo nos principais países capitalistas, a partir da década de 80 do século 20, traz em seu bojo um "recuo da atuação direta do Estado na economia" (NASCIMENTO, 2015, p. 198), que se faz acompanhar pela introdução de mudanças nos sistemas e estruturas de regulação econômica. A existência de um movimento global de reformas regulatórias impulsiona o interesse acadêmico pela regulação como uma forma de governança. Nesse contexto, a governança, por meio da regulação, deixou de ser uma peculiaridade dos Estados Unidos e passou a ser incorporada às reformas executadas pela União Europeia e por parte dos países em desenvolvimento (JORDANA; LEVI-FAUR, 2004), como o Brasil. 
Discutido em diversas disciplinas e sob diferentes perspectivas teóricas, o conceito de regulação assume significados variados na literatura (OLIVEIRA, 2014; NASCIMENTO, 2015) que expressam preocupações disciplinares específicas oriundos da aplicação de diferentes métodos de pesquisa (WINDHOLZ; HODGE, 2013). Baldwin et al. (1998 apud JORDANA; LEVI-FAUR, 2004) atribuem três significados principais ao termo: regras direcionadas; todas as formas de intervenção estatal na economia; e todos os mecanismos de controle social, independentemente de quem os exerça. O primeiro significado, mais restrito, expressa, nos termos de Baldwin, Scott e Hood (1998, p. 3), a "promulgação de um conjunto de regras, acompanhado por algum mecanismo, tipicamente um órgão público, para monitorar e promover o cumprimento dessas regras" e fazê-las valer, consoante a ideia de enforcement. O segundo significado, além da elaboração de regras e seu enforcement, compreende todos os esforços das instituições estatais para condução da economia, o que abrange a definição de subsídios e isenções tributárias dentre outros instrumentos de política pública. O terceiro, mais amplo, abarca todos os mecanismos de controle social, incluindo aqueles não oriundos das atividades do próprio Estado. Nessa acepção, qualquer aspecto que produza efeitos sobre o comportamento dos agentes em um dado campo de atividades pode ser considerado regulação (JORDANA; LEVI-FAUR, 2004; NASCIMENTO, 2015).

De acordo com Jordana, Levi-Faur e Marín (2011), a propagação de reformas regulatórias em âmbito global e a criação de instituições reguladoras independentes em diferentes setores da economia, acabaram popularizando o conceito mais restrito atribuído à regulação. Para os autores, o modelo de governança mais adequado para as economias capitalistas contemporâneas teria como base a criação de agências reguladoras independentes, o que constituiria a principal alternativa à tradicional organização burocrática do Estado. Ainda que os níveis de independência e autonomia das agências sejam distintos entre os diferentes países e setores, a criação dessas agências representaria um esforço para segregar as responsabilidades pela formulação e regulamentação das políticas públicas; assegurar a autonomia dos profissionais e especialistas no processo de efetivação das políticas públicas; e reduzir o risco de interferência política nas atividades regulatórias (JORDANA; LEVI-FAUR; MARÍN, 2011). Sem descurar a importância da independência e autonomia das agências reguladoras enquanto requisitos para garantir sua agilidade operacional e eficiência técnica, cabe observar, na linha da argumentação de José, Moraes e Hollnagel (2018, p. 111), a necessidade de submetê-las a controles, "tendo em vista que funcionam como o elo mediador entre o governo, usuários dos serviços públicos e empresas prestadoras de serviços".

Em consonância com o exposto, Minogue (2002) afirma que a era atual é caracterizada pela "governança regulatória", em que o mercado é considerado o melhor veículo para a provisão de serviços públicos e a maximização de riquezas individuais. Nesse cenário, novas regulações são frequentemente instituídas com o objetivo de promover a efetividade do mercado e a manutenção de serviços públicos adequados às necessidades e demandas da população, em uma busca constante pelo equilíbrio entre eficiência econômica e equidade/justiça social.

Na perspectiva econômica, a principal justificativa para a regulação estatal remete às denominadas falhas de mercado (SILVEIRA, 2006; MEIRELLES, 2010; OLIVEIRA, 2014; TRINDADE, 2019). A ocorrência dessas falhas relaciona-se a bens públicos, ex- 
ternalidades, assimetria de informações, poder de mercado e mercados incompletos (GALVÃO JÚNIOR; PAGANINI, 2009; TRINDADE, 2019). Para os propósitos do presente trabalho, importam mais diretamente as falhas relacionadas a externalidades e poder de mercado.

Externalidades são efeitos das atividades de produção e consumo que não se refletem diretamente no preço de mercado, provocando ineficiência econômica. Importa salientar a externalidade tipificada como positiva, a qual implica benefícios indiretos a terceiros, levando a uma oferta e um consumo inferiores ao que seria considerado desejável pela sociedade (PINDYCK; RUBINFELD, 2006), como ocorre na prestação dos serviços de saneamento básico. Por sua vez, o monopólio é observado nos casos em que a atuação em determinada atividade econômica é realizada por apenas uma empresa. Em relação a determinados serviços públicos, a exemplo do abastecimento de água e esgotamento sanitário, nos quais o mercado comporta apenas uma empresa para sua prestação, o monopólio é intitulado natural (GALVÃO JÚNIOR; PAGANINI, 2009; ARAúJO, BERTUSSI, 2018). Dada a ausência de concorrência, a empresa monopolista pode definir preço, quantidade produzida e qualidade do bem ou serviço ofertado, situação denominada pela literatura como poder de mercado (MEIRELLES, 2010). Adicionalmente, em decorrência da ausência de competição e da demanda inelástica de alguns serviços de utilidade pública, não existem incentivos para a redução dos custos e a melhoria da eficiência por parte das empresas monopolistas (JOURAVLEV, 2001).

A literatura aponta duas opções para lidar com as falhas do mercado - propriedade estatal $^{3}$ ou regulamentação -, as quais podem ser mobilizadas em simultâneo. A regulação, na concepção econômica, deve ser capaz de propiciar a harmonia entre a lucratividade das empresas, a qualidade dos serviços, o bem-estar da sociedade e os preços módicos aos usuários (SILVEIRA, 2006; SALGADO; MOTTA, 2005; SANTOS; KUWAJIMA; SANTANA, 2020). Trata-se de uma concepção que é associada, por diversos autores, à limitação das ações dos agentes de um dado campo de atividade a partir do poder de coerção do Estado (ABRANCHES, 1999). Isto se faz por meio de regras instituídas pelo ente estatal com vistas a coordenar e controlar as relações transacionais do mercado, cuja aplicação impacta todos os agentes envolvido no processo, refletindo-se no equilíbrio entre a oferta e a demanda.

Outros estudiosos, entretanto, ressaltam que, além da questão econômica, a regulação também abrange aspectos sociais, quando direcionada para proteção do interesse público (GALVÃO JÚNIOR, PAGANINI, 2009; TRINDADE, 2019). A instituição da regulação social estaria associada a duas motivações principais. A primeira afirma que a regulação econômica apresenta um caráter eminentemente técnico, focado nas faIhas de mercado, negligenciando questões de natureza distributiva que demandariam,

\footnotetext{
${ }^{3} \mathrm{Na}$ hipótese de propriedade estatal, a provisão dos bens e serviços é realizada diretamente pelo Estado que, nesse caso, representaria o interesse público e buscaria a maximização do bem-estar social. Ressalta-se, ainda, que historicamente a configuração de provisão de bens e serviços diretamente pelo Estado foi largamente utilizada como ferramenta para fomentação do desenvolvimento econômico de alguns países, principalmente na América Latina e Europa (GALVÃO JÚNIOR; PAGANINI, 2009). Ademais, apesar de a propriedade estatal ser apontada como uma alternativa à regulação, Marques Neto (2009a) elenca diversas questões para evidenciar a importância da regulação nas empresas estatais, tais como conflitos entre os interesses das instituições e seus administradores e o interesse público; ausência de segmentação e identificação dos papéis do regulado e regulador; e o fato de as empresas estatais apresentarem regime jurídico diverso da atividade regulatória, que deve ser tipicamente estatal.
} 
para sua observância, uma intervenção com viés social. A segunda afirma que a regulação social deveria viabilizar a construção de resultados superiores aos produzidos pela presumida operação eficiente dos mercados, que, por si só, seria incapaz de promover objetivos sociais relacionados à equidade, razoabilidade, justiça e coesão social (WINDHOLZ; HODGE, 2013).

Na prática, observa-se a existência de interdependência entre as regulações econômica e social (WINDHOLZ; HODGE, 2013). Considerando essa interdependência, Pires e Piccinini (1999) elencam diversos objetivos que justificam a instalação da regulação, que vão da busca pela eficiência econômica, assegurando a provisão de bens e serviços de qualidade e de menor custo para o consumidor ou usuário, à garantia da segurança e proteção do meio ambiente. Dentre esses objetivos inscreve-se a atuação com vistas à universalização da prestação dos serviços públicos, que se revestem de caráter de essencialidade à população, como os serviços de saneamento básico (ARAÚJO, BERTUSSI, 2018).

\section{SANEAMENTO BÁSICO NO BRASIL E A NECESSIDADE DA REGULAÇÃO}

O setor de saneamento básico no Brasil caracteriza-se por apresentar significativo déficit de atendimento, especialmente em relação aos serviços de esgotamento sanitário (TRATA BRASIL, 2018). Os indicadores setoriais referentes ao ano de 2018 mostram que aproximadamente $83,6 \%$ da população brasileira é atendida pelo serviço de abastecimento de água e $53,2 \%$ pelo serviço de coleta de esgoto, dos quais somente $46,3 \%$ é tratado (BRASIL, 2019a), conforme Tabela 1.

Tabela 1 - Níveis de atendimento com água e esgoto nos municípios cujos prestadores de serviços são participantes do SNIS (2018)

\begin{tabular}{lccccc}
\hline \multirow{2}{*}{ Macrorregião } & \multicolumn{3}{c}{ Índice de atendimento com rede (\%) } & $\begin{array}{c}\text { Tratamento dos } \\
\text { esgotos (\%) }\end{array}$ \\
\cline { 2 - 6 } & \multicolumn{2}{c}{ Água } & Coleta de esgoto & Esgotos gerados \\
\cline { 2 - 6 } & Total & Urbano & Total & Urbano & Total \\
\cline { 2 - 6 } & (IN055) & (IN023) & (IN056) & (IN024) & (IN046) \\
\hline Norte & 57,1 & 69,6 & 10,5 & 13,3 & 21,7 \\
Nordeste & 74,2 & 88,7 & 28,0 & 36,3 & 36,2 \\
Sudeste & 91,0 & 95,9 & 79,2 & 83,7 & 50,1 \\
Sul & 90,2 & 98,6 & 45,2 & 51,9 & 45,4 \\
Centro-Oeste & 89,0 & 96,0 & 52,9 & 58,2 & 53,9 \\
\hline Brasil & $\mathbf{8 3 , 6}$ & $\mathbf{9 2 , 8}$ & $\mathbf{5 3 , 2}$ & $\mathbf{6 0 , 9}$ & $\mathbf{4 6 , 3}$ \\
\hline \hline
\end{tabular}

Fonte: Brasil (2019a).

Em relação aos patamares de universalização do acesso aos serviços de abastecimento de água e esgotamento sanitário, Marques (2015, p. 247) afirma que

A prestação dos serviços continua seguindo uma clara lógica hierárquica em termos de grupos sociais, sendo os mais pobres servidos em proporções mais baixas e atendidos em último lugar, quando os serviços são escassos. Os estudos existentes sugerem ainda que os serviços para esses grupos apresentam pior qualidade. 
Em linha com o exposto, estudo publicado pela Comissão Econômica para a América Latina e o Caribe - Cepal - em 2018, mostrou que, para o ano de 2015, o acesso à água e ao esgotamento sanitário pela população brasileira era $18 \%$ maior entre os $20 \%$ mais ricos quando comparado aos níveis de acesso dos $20 \%$ mais pobres. A discrepância verificada foi a sexta mais alta entre 17 países latino-americanos e caribenhos. 0 estudo salientou, também, a existência de diferença na qualidade dos serviços prestados aos diferentes estratos da população, uma vez que as famílias de baixa renda são mais impactadas pela oferta de saneamento por soluções tecnológicas mais precárias e por situações de interrupções e intermitência dos serviços de abastecimento de água (CEPAL, 2018).

Como são reconhecidos como serviços públicos, as atividades de abastecimento de água e esgotamento sanitário devem ser organizadas e garantidas pelo Estado. Essa caracterização justifica-se em razão de questões sociais e econômicas, discutidas na seção anterior. Em relação à vertente social, o acesso ao serviço é fundamental para a manutenção do bem-estar da sociedade em virtude, principalmente, das inúmeras influências que exerce sobre a saúde pública - tanto na sua ausência quanto na sua presença, como evidencia, com nitidez, a atual pandemia da Covid-19. Por essa característica, uma série de princípios deve ser considerada na provisão dos serviços setoriais, tais como a universalidade, assegurando o atendimento a toda a sociedade; a continuidade, que se materializa na manutenção de um funcionamento contínuo e regular dos serviços; a equidade no tratamento aos usuários; o progresso e a contínua adaptação dos serviços ante a evolução das necessidades da sociedade; e a modicidade tarifária, que viabiliza o acesso aos serviços para todos os estratos da sociedade (BRITTO, 2011).

Em relação à vertente econômica, o setor de saneamento básico apresenta características que instrumentalizam a ocorrência de falhas de mercado. Galvão Júnior e Paganini (2009) relacionam as características físicas e econômicas do saneamento que evidenciam a obrigatoriedade da existência de regulação estatal, dentre as quais se incluem, no que se refere à necessidade de regulação, aspectos como a necessidade de estrutura adequada para o monitoramento da qualidade dos serviços prestados pelas concessionárias; a geração de externalidades positivas e negativas para a saúde pública, meio ambiente e recursos hídricos; e o monopólio natural, trazendo a possibilidade de extração de rendas significativas pelo prestador de serviços.

Considerando os aspectos sociais e econômicos salientados por Britto (2011) e Galvão Júnior e Paganini (2009), o objetivo da regulação do setor não se limita apenas a coibir as falhas de mercado e viabilizar o equilíbrio econômico-financeiro dos prestadores, posto que os reguladores terão "necessariamente, incumbências de assegurar o atingimento de objetivos postos nas políticas públicas setoriais, além de exercer um forte conteúdo de regulação social" (MARQUES NETO, 2009b, p. 178). É o que reconhece a Lei Federal n. 8.987 de 1995, conhecida como Lei das Concessões, segundo a qual, em seu artigo 60, além da manutenção do equilíbrio econômico-financeiro da prestação 
dos serviços, o ente regulador deve prezar pela "regularidade, continuidade, eficiência, segurança, atualidade, generalidade, cortesia na sua prestação e modicidade das tarifas $^{4}$ (BRASIL, 1995).

A necessidade de regulação para os serviços públicos de abastecimento de água e esgotamento sanitário foi estabelecida pela Lei n. 11.445/2007, independentemente do arranjo institucional adotado em sua prestação. A lei determina, em seu artigo $9^{\circ}$, que 0 titular deverá "prestar diretamente os serviços, ou conceder a prestação deles, e definir, em ambos os casos, a entidade responsável pela regulação e fiscalização da prestação dos serviços públicos de saneamento básico", sendo integrante ou não de sua estrutura administrativa. Define, ainda, que a regulação poderá ser delegada a "qualquer entidade reguladora, e o ato de delegação explicitará a forma de atuação e a abrangência das atividades a serem desempenhadas pelas partes envolvidas" (BRASIL, 2007, artigo 23). As agências reguladoras podem ser instituídas em âmbito estadual, municipal ou a partir de consórcios de regulação.

O artigo 21 da referida lei estabelece que a regulação poderá ser realizada somente por entidade de natureza autárquica dotada de independência decisória e autonomia administrativa, orçamentária e financeira, atribuindo, como princípios da regulação, a tecnicidade, a transparência, a celeridade e a objetividade das decisões (BRASIL, 2007). Por sua vez, o artigo 22 elenca seus objetivos conforme transcrito a seguir:

I- estabelecer padrões e normas para a adequada prestação e a expansão da qualidade dos serviços e para a satisfação dos usuários, com observação das normas de referência editadas pela ANA;

II - garantir o cumprimento das condições e metas estabelecidas nos contratos de prestação de serviços e nos planos municipais ou de prestação regionalizada de saneamento básico;

III - prevenir e reprimir o abuso do poder econômico, ressalvada a competência dos órgãos integrantes do Sistema Brasileiro de Defesa da Concorrência;

IV - definir tarifas que assegurem tanto o equilíbrio econômico-financeiro dos contratos quanto a modicidade tarifária, por mecanismos que gerem eficiência e eficácia dos serviços e que permitam o compartilhamento dos ganhos de produtividade com os usuários.

À entidade reguladora é imputada, portanto, a responsabilidade pela edição de normas relacionadas às dimensões econômicas, técnicas e sociais da prestação dos serviços, das quais destacam-se a definição do regime, estrutura e níveis tarifários, com os procedimentos e prazos de sua fixação, reajuste e revisão, bem como a incorporação de subsídios tarifários e não tarifários - um dos principais instrumentos utilizados para viabilizar a acessibilidade econômica aos serviços de abastecimento de água e esgotamento sanitário pela população dos estratos de baixa renda.

De acordo, entretanto, com a Associação Brasileira de Agências de Regulação Abar -, no ano de 2018 apenas 3.378 dos municípios brasileiros, 60,6\% do total, possuíam regulação para os serviços de abastecimento de água e esgotamento sanitário.

\footnotetext{
${ }^{4}$ Em relação à modicidade tarifária, Gasparini (2010) afirma que a administração pública é responsável pela elaboração e adoção de políticas públicas que busquem garantir que as tarifas dos serviços sejam justas e acessíveis a todos os usuários.
} 
Nos 2.192 municípios que ainda não contavam com a atividade reguladora, 39,4\% do total, os serviços são majoritariamente operados localmente (ABAR, 2019). Decorridos, portanto, mais de uma década da prescrição da necessidade de regulação setorial pela Lei n. 11.445/2007, ainda se observa um expressivo déficit regulatório no país, em que aspectos, como a política tarifária praticada na prestação do serviço, não seguem as prescrições legais, com o controle da atividade ficando circunscrita à esfera do poder concedente.

\section{A POLÍTICA TARIFÁRIA SETORIAL: Aspectos Normativos}

No Brasil, um dos princípios jurídicos relacionados à atividade de prestação de serviços públicos é o da modicidade tarifária. Prevista no artigo 60 da Lei das Concessões, o princípio determina que o gestor público estabeleça políticas tarifárias de forma a viabilizar o acesso aos serviços pela população economicamente vulnerável (BRASIL, 1995). Nesse contexto, as políticas públicas relativas ao saneamento básico devem se assentar no princípio de que a provisão adequada dos serviços é um direito do cidadão, independentemente de qualquer aspecto de distinção social.

Os serviços públicos que demandam grandes custos de operação e que necessitam de elevados investimentos são dependentes, na maioria das vezes, de políticas de subsídios como ferramenta de financiamento. Esse mecanismo é utilizado, em particular, para viabilizar o processo de universalização dos serviços, garantir o equilíbrio econômico-financeiro da concessionária e assegurar o acesso aos serviços pela população economicamente vulnerável (PEIXOTO, 2013; MOREIRA, 1998).

A utilização de subsídios públicos na área de saneamento básico é uma prática antiga e amplamente verificada em diversas partes do mundo. No Brasil, os subsídios foram a principal forma de financiamento para realização de investimentos e para parte do custeio dos serviços de abastecimento de água e esgotamento sanitário até a década de 70 do século 20 (PEIXOTO, 2013). Mais recentemente, a Lei 11.445/2007, em seu artigo 3으, prevê a possibilidade de instituição de subsídios, definindo-os como "instrumentos econômicos de política social que contribuem para a universalização do acesso aos serviços públicos de saneamento básico por parte de populações de baixa renda" (BRASIL, 2007). Por sua vez, o seu artigo 29, transcrito a seguir, traz os principais aspectos da política tarifária setorial.

Art. 29. Os serviços públicos de saneamento básico terão a sustentabilidade econômico-financeira assegurada por meio de remuneração pela cobrança dos serviços, e, quando necessário, por outras formas adicionais, como subsídios ou subvenções, vedada a cobrança em duplicidade de custos administrativos ou gerenciais a serem pagos pelo usuário, nos seguintes serviços:

I- de abastecimento de água e esgotamento sanitário, na forma de taxas, tarifas e outros preços públicos, que poderão ser estabelecidos para cada um dos serviços ou para ambos, conjuntamente;

$[\ldots]$

$\S 1$ O Observado o disposto nos incisos I a III do caput deste artigo, a instituição das tarifas, preços públicos e taxas para os serviços de saneamento básico observará as seguintes diretrizes: 
I - prioridade para atendimento das funções essenciais relacionadas à saúde pública;

II - ampliação do acesso dos cidadãos e localidades de baixa renda aos serviços;

III - geração dos recursos necessários para realização dos investimentos, objetivando o cumprimento das metas e objetivos do serviço;

IV - inibição do consumo supérfluo e do desperdício de recursos;

V - recuperação dos custos incorridos na prestação do serviço, em regime de eficiência;

$\mathrm{VI}$ - remuneração adequada do capital investido pelos prestadores dos serviços;

VII - estímulo ao uso de tecnologias modernas e eficientes, compatíveis com os níveis exigidos de qualidade, continuidade e segurança na prestação dos serviços;

VIII - incentivo à eficiência dos prestadores dos serviços.

§ 2ㅇ Poderão ser adotados subsídios tarifários e não tarifários para os usuários que não tenham capacidade de pagamento suficiente para cobrir o custo integral dos serviços.

$[\ldots]$

De acordo com o artigo 30, a capacidade de pagamento dos consumidores é um dos fatores que devem ser levados em consideração no desenvolvimento da estrutura tarifaria dos serviços públicos de saneamento básico.

Em relação à origem dos recursos, o artigo 31 define que os subsídios podem ser de origem tarifária ou fiscal e internos a cada titular ou entre titulares, nas hipóteses de prestação regionalizada (BRASIL, 2007). Os subsídios tarifários são constituídos dentro da própria estrutura de cobrança, sendo pagos por determinadas classes ou categorias de usuários; os de origem fiscal, por sua vez, são provenientes de recursos orçamentários dos entes públicos, independentemente de sua fonte de arrecadação, sendo também denominados subvenções ou subsídios públicos (PEIXOTO, 2013). Vale ressaltar que, nos últimos anos, tem-se observado uma redução significativa e constante dos recursos oriundos dos orçamentos das três esferas do governo, o que impulsiona a utilização de subsídios tarifários para a expansão e a manutenção dos serviços para a população de baixa renda.

Instituído ainda na época do Planasa com o objetivo de universalizar os serviços de saneamento básico, o subsídio ao consumo, inserido na própria estrutura tarifária, recebe a nomenclatura de "subsídio cruzado", que continua sendo a modalidade mais utilizada pelo setor. O Decreto Federal n. 82.587, de 6 de novembro de 1978 (revogado em 1991), que estabelecia as normas gerais de tarifação para os serviços públicos setoriais integrados ao Planasa, já previa, em seus artigos 10 e 11, transcritos na sequência, a instituição de subsídios para viabilização da acessibilidade econômica.

Art. 10 - Os benefícios dos serviços de saneamento básico serão assegurados a todas as camadas sociais, devendo as tarifas adequar-se ao poder aquisitivo da população atendida, de forma a compatibilizar os aspectos econômicos com os objetivos sociais.

Art. 11 - As tarifas deverão ser diferenciadas segundo as categorias de usuários e faixas de consumo, assegurando-se o subsídio dos usuários de maior para os de menor poder aquisitivo, assim como dos grandes para os pequenos consumidores. 
Os subsídios cruzados podem ser explícitos ou implícitos. Em razão da possibilidade de mensurar o valor subsidiado, são considerados explícitos os subsídios realizados entre estratos sociais para viabilizar o acesso aos serviços pela população de baixa renda. Por outro lado, os subsídios cruzados implícitos são aqueles em que não é possível determinar o valor subsidiado. Essa modalidade é usualmente verificada nas empresas de saneamento estaduais que adotam tarifa única para todos os municípios atendidos, inviabilizando a mensuração dos recursos transferidos entre localidades (CRUZ; RAMOS, 2016).

Nesse contexto, o subsídio cruzado deve concentrar-se nas localidades e usuários que apresentem escala econômica e/ou capacidade de pagamento insuficientes, situações que acabam inviabilizando os investimentos sob a lógica de mercado e o acesso ao serviço. A concessão de benefícios de forma direta e proporcional à renda dos usuários é considerada uma das melhores alternativas para a democratização do acesso aos serviços de saneamento (PEIXOTO, 2013).

A definição de tarifas adequadas à capacidade de pagamento, de forma que os usuários com melhores condições socioeconômicas assumam uma maior parcela dos custos necessários à manutenção e ampliação da cobertura dos serviços, garante, portanto, o equilíbrio econômico-financeiro da concessionária e a modicidade tarifária dos usuários com acesso aos serviços. $O$ instrumento tarifário que reduz as tarifas da população de baixa renda de forma a promover o acesso aos serviços de utilidade pública por todos os estratos da população, é a denominada Tarifa Social, aplicável ao setor de saneamento básico.

\section{METODOLOGIA}

Para avaliar o nível de adoção da Tarifa Social na prestação dos serviços de saneamento básico no território nacional, utilizou-se a base de dados disponibilizada pelo SNIS referente aos serviços de abastecimento de água e esgotamento sanitário para o exercício de 2018.

Foi realizada a compilação dos seguintes dados concernentes aos munícipios atendidos pelas concessionárias participantes do SNIS: município; UF; nome, sigla, abrangência e natureza jurídica dos prestadores serviços; tipo de serviço prestado; quantidade de municípios atendidos com abastecimento de água; quantidade de municípios atendidos com esgotamento sanitário; e ocorrência de cobrança de Tarifa Social (Brasil, 2019b). Tais dados foram disponibilizados pelo SNIS em tabelas anexas ao Diagnóstico dos Serviços de Água e Esgotos - 2018 -, publicado pelo Ministério do Desenvolvimento Regional em arquivos segregados por prestadores de serviços de abrangência local (empresa privada, direito privado com administração pública, direito público), microrregional e regional.

Após a mensuração dos municípios que possuíam a Tarifa Social no exercício de 2018 e da quantidade de municípios atendidos por empresas regionais de saneamento básico, verificou-se, a partir de revisão documental de estudo publicado pela Abar (2018), os critérios adotados por algumas concessionárias estaduais para concessão do benefício.

Buscou-se, portanto, verificar a amplitude e utilização da Tarifa Social para os serviços de abastecimento sanitário e esgotamento sanitário no Brasil e a adequação dos critérios adotados para sua concessão ao principal objetivo da política. 


\section{A TARIFA SOCIAL NO SETOR DE SANEAMENTO BÁSICO}

Ao viabilizar e promover o acesso da população de baixa renda aos serviços de utilidade pública, a Tarifa Social constitui-se como uma das mais importantes ferramentas para criação de políticas públicas no âmbito das políticas tarifárias (ALMEIDA, 2009). Ainda que não existam normas ou diretrizes gerais que obriguem sua instituição no setor de saneamento básico, observa-se um significativo nível de adoção por parte de prestadores de serviços atuantes na área, especialmente aqueles com atuação de abrangência regional. As características dos prestadores de serviços de abastecimento de água e esgotamento sanitário, segundo a abrangência e cobertura de atendimento no país para o ano de 2018, podem ser visualizadas na Tabela 2, de acordo com informações do SNIS (BRASIL, 2019a).

Tabela 2 - Distribuição dos prestadores de serviços participantes do SNIS segundo abrangência e atendimento (2018)

\begin{tabular}{lccccc}
\hline \multicolumn{2}{c}{ Prestadores de serviços } & \multicolumn{2}{c}{$\begin{array}{c}\text { Quantidade de municípios } \\
\text { atendidos }\end{array}$} & \multicolumn{2}{c}{$\begin{array}{c}\text { População urbana dos } \\
\text { municípios }\end{array}$} \\
\hline Abrangência & Quantidade & Água & Esgotos & Água & Esgotos \\
\hline Regional & 28 & 4.029 & 1.403 & 129.754 .872 & 105.341 .765 \\
Microrregional & 8 & 35 & 20 & 928.927 & 826.207 \\
Local & 1.532 & 1.102 & 1.107 & 44.830 .494 & 52.547 .831 \\
\hline Total & $\mathbf{1 . 5 6 8}$ & $\mathbf{5 . 1 6 6}$ & $\mathbf{2 . 5 3 0}$ & $\mathbf{1 7 5 . 5 1 4 . 2 9 3}$ & $\mathbf{1 5 8 . 7 1 5 . 8 0 3}$ \\
\hline \hline
\end{tabular}

Notas: a) Nos casos em que há dois prestadores com a mesma abrangência que atendam a um município com o mesmo serviço, foram excluídas as repetições para evitar duplicação na quantidade de municípios atendidos e na totalização da população urbana. b) Já nos casos em que há um prestador de serviços regional e um outro local que atendem aos mesmos municípios com um serviço, não estão excluídas as repetições. Isso se deve ao fato de as abrangências dos prestadores de serviços serem diferentes, não sendo possível definir em qual campo seria feito o desconto da repetição. Fonte: Brasil (2019a, p. 31).

Os prestadores de serviços de abrangência regional correspondem a 1,79\% do total, atendendo aproximadamente a $73,93 \%$ e $66,37 \%$ da população urbana com serviços de abastecimento de água e esgotamento sanitário, respectivamente; para os de abrangência microrregional, 0,51\% do total, a participação é de 0,53\% e 0,52\%, respectivamente; já os de abrangência local, $97,7 \%$ do total, o índice de atendimento é de $25,54 \%$ e $33,11 \%$, respectivamente.

Os dados disponibilizados pelo SNIS (BRASIL, 2018) referentes à adoção da Tarifa Social referem-se a 5.136 municípios, que correspondem a aproximadamente $92 \%$ do total. A Tabela 3 apresenta o quantitativo de municípios que a instituíram de acordo com a abrangência do prestador de serviços.

Tabela 3 - Quantidade de municípios que instituíram a Tarifa Social de acordo com a abrangência do prestador de serviços, em 2018

\begin{tabular}{|c|c|c|c|}
\hline \multirow{2}{*}{$\begin{array}{l}\text { Abrangência do } \\
\text { prestador de serviços }\end{array}$} & \multicolumn{2}{|c|}{ Municípios participantes do SNIS } & \multirow{2}{*}{$\begin{array}{l}\text { Total de municípios } \\
\text { participantes do SNIS }\end{array}$} \\
\hline & Com Tarifa Social & Sem Tarifa Social & \\
\hline Local & 319 & 754 & 1.073 \\
\hline Micro & 32 & 2 & 34 \\
\hline Regional & 3.519 & 62 & 3.581 \\
\hline Local e Regional & 444 & 3 & 447 \\
\hline Micro e Regional & 1 & - & 1 \\
\hline Total & 4.315 & 821 & 5.136 \\
\hline
\end{tabular}

Fonte: Elaboração própria a partir de dados SNIS (BRASIL, 2018). 
Em 2018 a Tarifa Social encontrava-se instituída em 84\% dos municípios participantes do SNIS. Quanto à área de abrangência do prestador dos serviços, sua adoção comparece em aproximadamente $98 \%$ dos municípios em que a concessão é de empresa regional; proporção que se reduz para somente cerca de $30 \%$ naqueles atendidos por prestadores locais, nos quais, como visto anteriormente, a regulação por meio de agência reguladora ocorre com frequência significativamente menor.

$\mathrm{Na}$ Tabela 4 é apresentada a relação de empresas regionais que atuam no setor de saneamento básico e a quantidade de municípios em que prestam os serviços de abastecimento de água e/ou esgotamento sanitário no Brasil, conforme informações agregadas disponibilizadas pelo SNIS (BRASIL, 2018).

Tabela 4 - Empresas regionais de saneamento básico e quantidade de municípios atendidos com os serviços de abastecimento de água e esgotamento sanitário, em 2018

\begin{tabular}{|c|c|c|c|c|c|c|c|}
\hline Região & UF & $\begin{array}{l}\text { Compa- } \\
\text { nhias Es- } \\
\text { taduais de } \\
\text { Saneamen- } \\
\text { to Básico } \\
\text { - Cesb (1) }\end{array}$ & $\begin{array}{l}\text { Total de } \\
\text { muni- } \\
\text { cípios } \\
\text { (IBGE) }\end{array}$ & $\begin{array}{l}\text { Quantidade } \\
\text { de municípios } \\
\text { atendidos com } \\
\text { abastecimento } \\
\text { de água }\end{array}$ & $\begin{array}{c}\text { \% em } \\
\text { relação ao } \\
\text { total de } \\
\text { municípios } \\
\text { da UF }\end{array}$ & $\begin{array}{l}\text { Quantidade } \\
\text { de municípios } \\
\text { atendidos com } \\
\text { esgotamento } \\
\text { sanitário }\end{array}$ & $\begin{array}{l}\text { \% em } \\
\text { relação ao } \\
\text { total de } \\
\text { municípios } \\
\text { da UF }\end{array}$ \\
\hline \multirow{8}{*}{ Norte } & $A C$ & Depasa & 22 & 22 & 100,00 & 1 & 4,55 \\
\hline & AM & Cosama & 62 & 12 & 19,35 & 0 & 0,00 \\
\hline & AP & Caesa & 16 & 16 & 100,00 & 6 & 37,50 \\
\hline & PA & Cosanpa & 144 & 53 & 36,81 & 5 & 3,47 \\
\hline & RO & Caerd & 52 & 37 & 71,15 & 2 & 3,85 \\
\hline & $\mathrm{RR}$ & Caer & 15 & 15 & 100,00 & 1 & 6,67 \\
\hline & TO & Saneatins & 139 & 52 & 37,41 & 13 & 9,35 \\
\hline & то & ATS & 139 & 70 & 50,36 & 0 & 0,00 \\
\hline \multirow{9}{*}{ Nordeste } & AL & Casal & 102 & 76 & 74,51 & 12 & 11,76 \\
\hline & BA & Embasa & 417 & 366 & 87,77 & 106 & 25,42 \\
\hline & $\mathrm{CE}$ & Cagece & 184 & 152 & 82,61 & 74 & 40,22 \\
\hline & MA & Caema & 217 & 140 & 64,52 & 4 & 1,84 \\
\hline & PB & Cagepa & 223 & 196 & 87,89 & 22 & 9,87 \\
\hline & $\mathrm{PE}$ & Compesa & 185 & 173 & 93,51 & 31 & 16,76 \\
\hline & $\mathrm{PI}$ & Agespisa & 224 & 156 & 69,64 & 11 & 4,91 \\
\hline & RN & Caern & 167 & 156 & 93,41 & 43 & 25,75 \\
\hline & SE & Deso & 75 & 73 & 97,33 & 6 & 8,00 \\
\hline \multirow{3}{*}{$\begin{array}{l}\text { Centro- } \\
\text { Oeste }\end{array}$} & DF & Caesb & 1 & 1 & 100,00 & 1 & 100,00 \\
\hline & GO & Saneago & 246 & 225 & 91,46 & 74 & 30,08 \\
\hline & MS & Sanesul & 79 & 68 & 86,08 & 49 & 62,03 \\
\hline
\end{tabular}




\begin{tabular}{lllccccc}
\hline \multirow{5}{*}{ Sudeste } & ES & Cesan & 78 & 52 & 66,67 & 30 & 38,46 \\
& MG & Copanor ${ }^{(2)}$ & 853 & 78 & 9,14 & 49 & 5,74 \\
& MG & Copasa ${ }^{(2)}$ & 853 & 581 & 68,11 & 220 & 25,79 \\
& RJ & Cedae & 92 & 64 & 69,57 & 23 & 25,00 \\
& SP & Sabesp & 645 & 369 & 57,21 & 368 & 57,05 \\
\hline \multirow{4}{*}{ Sul } & PR & Sanepar & 399 & 345 & 86,47 & 189 & 47,37 \\
& RS & Corsan & 497 & 316 & 63,58 & 52 & 10,46 \\
& SC & Casan & 295 & 196 & 66,44 & 21 & 7,12 \\
\hline
\end{tabular}

(1) Depasa - Departamento Estadual de Água e Saneamento do Acre; Casal - Companhia de Saneamento de Alagoas; Cosama Companhia de Saneamento do Amazonas; Caesa - Companhia de Água e Esgoto do Amapá; Embasa - Empresa Baiana de Águas e Saneamento S.A.; Cagece - Companhia de Água e Esgoto do Ceará; Caesb - Companhia de Saneamento Ambiental do Distrito Federal; Cesan - Companhia Espírito-Santense de Saneamento; Saneago - Companhia Saneamento de Goiás S.A.; Caema - Companhia de Saneamento Ambiental do Maranhão; Copasa - Companhia de Saneamento de Minas Gerais; Copanor - Copasa Serviços de Saneamento Integrado do Norte e Nordeste de Minas Gerais S.A.; Sanesul - Empresa de Saneamento de Mato Grosso do Sul S.A.; Cosanpa - Companhia de Saneamento do Pará; Cagepa - Companhia de Águas e Esgotos da Paraíba; Compesa - Companhia Pernambucana de Saneamento; Agespisa - Águas e Esgotos do Piauí S.A.; Sanepar - Companhia de Saneamento do Paraná; Cedae - Companhia Estadual de Águas e Esgotos; Caern - Companhia de Águas e Esgotos do Rio Grande do Norte; Caerd - Companhia de Águas e Esgotos de Rondônia; Caer - Companhia de Águas e Esgotos de Roraima; Corsan - Companhia Rio-Grandense de Saneamento; Casan - Companhia Catarinense de Águas e Saneamento; Deso - Companhia de Saneamento de Sergipe; Sabesp Companhia de Saneamento Básico do Estado de São Paulo; Saneatins - Companhia de Saneamento do Tocantins; ATS - Agência Tocantinense de Saneamento

(2) Em alguns municípios mineiros os serviços de abastecimento de água e esgotamento sanitário são prestados, simultaneamente, pela Copasa e Copanor.

Fonte: Elaboração própria, a partir de dados SNIS (BRASIL, 2018).

Com exceção de Mato Grosso, todas as demais unidades federativas possuem ao menos uma empresa de saneamento com atuação em âmbito regional. O benefício da Tarifa Social está presente em todas as empresas regionais, exceto na Cosama e Cosanpa. Em razão da possibilidade de instituição do subsídio cruzado entre os diversos municípios atendidos, bem como de uma maior probabilidade de existência de entidades independentes para regulação e fiscalização dos serviços, verifica-se uma maior tendência de instituição da Tarifa Social nos municípios atendidos por empresas regionais. 0 caráter, no entanto, não obrigatório de sua aplicação, abre espaço para condutas como as da Cosama e da Cosanpa, que não se veem institucionalmente constrangidas a adotá-la.

Em contrapartida, na maior parte dos municípios em que a prestação dos serviços é realizada por empresa local, principalmente aqueles considerados de pequeno porte, a escala do atendimento tende a dificultar a aplicação da Tarifa Social, uma vez que o estabelecimento de subsídios entre as diferentes categorias de usuários pode onerar em demasia os estratos de renda mais elevados, indo de encontro ao princípio da modicidade tarifária. Adicionalmente, concentra-se nesses municípios o descumprimento da norma legal de adoção da regulação por agência reguladora. A Tabela 5 apresenta os resultados referentes à proporção de municípios, por Estado, que instituíram a Tarifa Social para os serviços de abastecimento de água e esgotamento sanitário.

Tabela 5 - Proporção de municípios que instituíram a Tarifa Social - por Unidade Federativa 


\begin{tabular}{|c|c|c|c|c|c|c|}
\hline Região & UF & $\begin{array}{c}\text { Total de } \\
\text { municípios } \\
\text { (IBGE) }\end{array}$ & $\begin{array}{c}\text { Quantidade } \\
\text { de municípios } \\
\text { atendidos com } \\
\text { abastecimento de } \\
\text { água } \\
\end{array}$ & $\begin{array}{l}\text { \% em relação } \\
\text { ao total de } \\
\text { municípios } \\
\text { do Estado }\end{array}$ & $\begin{array}{l}\text { Quantidade } \\
\text { de municípios } \\
\text { atendidos com } \\
\text { esgotamento } \\
\text { sanitário } \\
\end{array}$ & $\begin{array}{c}\text { \% em relação } \\
\text { ao total de } \\
\text { municípios } \\
\text { do Estado }\end{array}$ \\
\hline \multirow{7}{*}{ Norte } & $A C$ & 22 & 22 & 100 & 1 & 4,55 \\
\hline & AM & 62 & 2 & 3,23 & 1 & 1,61 \\
\hline & AP & 16 & 16 & 100,00 & 6 & 37,50 \\
\hline & PA & 144 & 16 & 11,11 & 5 & 3,47 \\
\hline & RO & 52 & 42 & 80,77 & 6 & 11,54 \\
\hline & $\mathrm{RR}$ & 15 & 15 & 100,00 & 1 & 6,67 \\
\hline & TO & 139 & 129 & 92,81 & 14 & 10,07 \\
\hline \multirow{9}{*}{ Nordeste } & $\mathrm{AL}$ & 102 & 80 & 78,43 & 16 & 15,69 \\
\hline & BA & 417 & 374 & 89,69 & 113 & 27,10 \\
\hline & CE & 184 & 158 & 85,87 & 79 & 42,93 \\
\hline & MA & 217 & 148 & 68,20 & 9 & 4,15 \\
\hline & PB & 223 & 196 & 87,89 & 22 & 9,87 \\
\hline & PE & 185 & 174 & 94,05 & 31 & 16,76 \\
\hline & $\mathrm{PI}$ & 224 & 158 & 70,54 & 13 & 5,80 \\
\hline & $\mathrm{RN}$ & 167 & 159 & 95,21 & 46 & 27,54 \\
\hline & SE & 75 & 74 & 98,67 & 6 & 8,00 \\
\hline \multirow{4}{*}{$\begin{array}{l}\text { Centro- } \\
\text { Oeste }\end{array}$} & DF & 1 & 1 & 100,00 & 1 & 100,00 \\
\hline & GO & 246 & 228 & 92,68 & 77 & 31,30 \\
\hline & MS & 79 & 72 & 91,14 & 53 & 67,09 \\
\hline & MT & 141 & 21 & 14,89 & 12 & 8,51 \\
\hline \multirow{4}{*}{ Sudeste } & ES & 78 & 55 & 70,51 & 33 & 42,31 \\
\hline & MG & 853 & 688 & 80,66 & 314 & 36,81 \\
\hline & RJ & 92 & 78 & 84,78 & 41 & 44,57 \\
\hline & SP & 645 & 450 & 69,77 & 448 & 69,46 \\
\hline \multirow{3}{*}{ Sul } & PR & 399 & 358 & 89,72 & 196 & 49,12 \\
\hline & RS & 497 & 351 & 70,62 & 67 & 13,48 \\
\hline & SC & 295 & 250 & 84,75 & 46 & 15,59 \\
\hline Total & & 5.570 & 4.315 & 77,47 & 1.657 & 29,75 \\
\hline
\end{tabular}

Fonte: Elaboração própria a partir de dados SNIS (BRASIL, 2018).

Verifica-se, portanto, que a Tarifa Social para os serviços de abastecimento de água e esgotamento sanitário está presente em, ao menos, $77,47 \%$ e $29,75 \%$ dos municípios brasileiros, respectivamente. O Estado do Amazonas é aquele que apresenta os menores índices de municípios que instituíram o benefício, refletindo o fato de sua empresa regional de saneamento básico não aplicá-lo: dos 62 municípios do Estado, em apenas dois há a sua ocorrência para os serviços de água e somente um para os serviços de esgotamento 
sanitário. Em contrapartida, 91,14\% e 67,09\% dos municípios do Estado do Mato Grosso Sul possuem Tarifa Social para os serviços de água e esgoto, respectivamente. Trata-se de Estado em que a empresa regional de saneamento básico, que aplica o benefício, é responsável pela prestação dos serviços na ampla maioria de seus municípios.

Salienta-se, ainda, a existência de uma diversidade de formas de regulamentação da Tarifa Social para os serviços de abastecimento de água e esgotamento sanitário, tais como as leis, decretos, portarias e resoluções, o que abrange as resoluções emitidas pelas agências reguladoras. Essa heterogeneidade espelha a ausência de diretrizes para o tratamento da matéria no âmbito do marco normativo setorial. A Tarifa Social é mencionada uma única vez na Lei n. 11.445/2007, que se limita a determinar, em seu artigo 40, que a restrição ou interrupção de fornecimento de água por inadimplência de usuários enquadrados como seus beneficiários deverá observar prazos e critérios que promovam a manutenção da saúde das pessoas atingidas (BRASIL, 2007). ${ }^{5}$

Estudo realizado pela Abar (2018) buscou avaliar os critérios adotados por algumas das empresas regionais de saneamento para o acesso à Tarifa Social. O Quadro 1 apresenta a compilação dos principais critérios utilizados pelas empresas que participaram do estudo, referentes a 2017.

Quadro 1 - Critérios adotados para concessão da Tarifa Social, em 2017

\begin{tabular}{|lcccccccccc|}
\hline Cesb & $\begin{array}{c}\text { Adim- } \\
\text {-plência } \\
\text { na Cesb }\end{array}$ & $\begin{array}{c}\text { Auto- } \\
\text { móvel }\end{array}$ & $\begin{array}{c}\text { Caracterís- } \\
\text { ticas cons- } \\
\text { trutivas do } \\
\text { imóvel }\end{array}$ & $\begin{array}{c}\text { Consu- } \\
\text { mo de } \\
\text { água }\end{array}$ & $\begin{array}{c}\text { Consu- } \\
\text { mo de } \\
\text { energia }\end{array}$ & $\begin{array}{c}\text { Fonte } \\
\text { alterna- } \\
\text { tiva de } \\
\text { água }\end{array}$ & $\begin{array}{c}\text { Node } \\
\text { econo- } \\
\text { mias por } \\
\text { ligação }\end{array}$ & $\begin{array}{c}\text { Pro- } \\
\text { gramas } \\
\text { sociais }\end{array}$ & $\begin{array}{c}\text { Ren- } \\
\text {-da }\end{array}$ & $\begin{array}{c}\text { Usuário } \\
\text { com } \\
\text { cadastro } \\
\text { único na } \\
\text { CESB }\end{array}$ \\
\hline Caesb & - & - & $\checkmark$ & $\checkmark$ & - & - & - & - & - & - \\
Cagece & - & - & $\checkmark$ & $\checkmark$ & - & - & $\checkmark$ & $\checkmark$ & - & - \\
Casal & - & - & $\checkmark$ & - & - & - & $\checkmark$ & $\checkmark$ & $\checkmark$ & - \\
Casan & - & $\checkmark$ & $\checkmark$ & - & - & - & - & - & $\checkmark$ & - \\
Cesan & - & - & - & - & - & - & - & $\checkmark$ & - & - \\
Copasa & - & - & - & - & - & - & - & $\checkmark$ & $\checkmark$ & - \\
Corsan & - & - & $\checkmark$ & - & - & - & - & $\checkmark$ & - & - \\
Depasa & - & - & $\checkmark$ & - & $\checkmark$ & - & - & $\checkmark$ & - & - \\
Deso & $\checkmark$ & - & - & - & - & - & - & - & - & $\checkmark$ \\
Sabesp & $\checkmark$ & - & $\checkmark$ & - & $\checkmark$ & - & - & - & $\checkmark$ & - \\
Saneago & - & - & $\checkmark$ & $\checkmark$ & - & $\checkmark$ & - & $\checkmark$ & $\checkmark$ & - \\
Sanepar & - & - & $\checkmark$ & $\checkmark$ & - & - & - & - & $\checkmark$ & - \\
Sanesul & $\checkmark$ & - & $\checkmark$ & $\checkmark$ & $\checkmark$ & - & - & - & $\checkmark$ & - \\
Total & $\mathbf{3}$ & $\mathbf{1}$ & $\mathbf{1 0}$ & $\mathbf{5}$ & $\mathbf{3}$ & $\mathbf{1}$ & $\mathbf{2}$ & $\mathbf{7}$ & $\mathbf{7}$ & $\mathbf{1}$ \\
\hline
\end{tabular}

Fonte: ABAR (2018).

\footnotetext{
5 Ressalta-se que tramita na Câmara dos Deputados o Projeto de Lei 9.543/2018, que "Cria a Tarifa Social de Água e Esgoto". O PL propõe a renda per capita de até meio salário mínimo como único critério para acesso ao benefício, atribuindo às faturas um desconto cumulativo de acordo com o nível de consumo das famílias: $40 \%$ para a faixa de consumo de até $10 \mathrm{~m}^{3} / \mathrm{mês} ; 30 \%$ para a faixa de consumo de 10 a $15 \mathrm{~m}^{3} / \mathrm{mês}$; e $20 \%$ para a faixa de 15 a $20 \mathrm{~m}^{3} / \mathrm{mês}^{2}$. Para a parcela de consumo superior a $20 \mathrm{~m}^{3} / \mathrm{mês}$, não seria atribuído qualquer tipo de desconto.
} 
O critério mais comumente utilizado refere-se às caraterísticas do imóvel, aplicado por $76,9 \%$ das empresas pesquisadas. A maior parte delas adota limites para a área construída, que variam de $40 \mathrm{~m}^{2}$ a $70 \mathrm{~m}^{2}$.

A renda é utilizada por pouco mais da metade das empresas pesquisadas, $53,8 \%$ do total. Ao lado disso, observa-se um alto grau de heterogeneidade em sua utilização, comparecendo, como parâmetros, a renda per capita e/ou a renda familiar. O limite per capita mais empregado é o de 0,5 salários mínimos, à medida que, para o valor familiar, as concessionárias atribuem limites que variam de um a três salários mínimos. A participação em programas sociais é outro requisito também utilizado por $53,8 \%$ das empresas pesquisadas. A maior parte delas exige cadastro em qualquer programa social, tanto de âmbito federal (Cadúnico) quanto estadual ou municipal.

Os demais critérios comparecem com frequência inferior a $50 \%$ das empresas pesquisadas, como o volume de água consumido, adotado por 38,5\% do total. Cabe ressaltar, no entanto, que outras empresas, somando $46,1 \%$ do total, limitam o desconto a determinadas faixas de consumo, que variam de $10 \mathrm{~m}^{2}$ e $35 \mathrm{~m}^{2}$. Apenas em duas empresas o acesso ao benefício não é limitado em razão do nível de consumo por economia.

No que diz respeito ao consumo de energia, adotado como critério por $23,1 \%$ do total, verificou-se a imposição de limites que variam de 80 a $170 \mathrm{KWh}$ por mês para concessão do benefício. Igual percentual utiliza, como critério, a adimplência junto a empresa. Por fim, somente uma empresa condiciona a concessão do benefício à inexistência de automóvel em propriedade da família e outra verifica se a residência não possui uma fonte alternativa de abastecimento de água.

Um ponto central em relação à concessão da Tarifa Social refere-se à definição do perfil de usuário de baixa renda e dos critérios utilizados para a concessão do benefício. Para o estabelecimento de uma política efetivamente inclusiva, é necessário que os prestadores possuam informações que permitam realizar a caracterização dos usuários dos serviços e a avaliação de sua capacidade de pagamento, de forma a definir o nível de redução tarifária necessária para a promoção do acesso aos serviços. O que se observa quanto aos critérios utilizados pelos prestadores para concessão do benefício, para além de sua heterogeneidade, é que alguns deles aparecem dissociados do principal objetivo da política, ou seja, o de viabilizar o acesso aos serviços por parte da população economicamente vulnerável.

\section{CONCLUSÕES}

A pandemia da Covid-19 reforçou a essencialidade da prestação adequada de serviços de saneamento básico, posta, em resolução da ONU, como direito humano essencial. No Brasil, a garantia desse direito esbarra no expressivo déficit de atendimento na prestação dos serviços setoriais, notadamente quanto ao esgotamento sanitário, o qual denota os limites da política tarifária e, por extensão, dos mecanismos de regulação, na alavancagem dos investimentos na expansão do sistema.

Independentemente da realização desses investimentos, no entanto, o fato de a acessibilidade ao serviço prestado ficar condicionada ao pagamento por parte do usuário, tende a constituir, para a população de baixa renda, um fator limitante à sua fruição. 
Um dos principais instrumentos para lidar com esse tipo de restrição é a Tarifa Social, aplicável ao setor, que se ancora na adoção de subsídios cruzados entre diferentes categorias de usuários.

Ainda que não exista qualquer tipo de regramento nacional que determine a efetivação da Tarifa Social para os serviços de saneamento básico, o benefício já foi instituído na maior parte dos municípios brasileiros - 4.315 -, correspondendo a $84,0 \%$ daqueles que participavam do SNIS em 2018 e a 77,4\% do total existente no país. Sua aplicação revela-se mais disseminada nos municípios em que a prestação dos serviços é realizada por empresa regional, quando alcança aproximadamente $98,0 \%$ do total, contra cerca de $30 \%$ do total atendido por prestadores locais. Verifica-se, além disso, grande heterogeneidade nos critérios adotados para sua concessão, que, muitas vezes, se dissociam do principal objetivo da política, situação que pode restringir o acesso de potenciais beneficiários.

A desejada universalização do acesso aos serviços de saneamento básico passa, portanto, por aprimoramentos nos arranjos regulatórios do setor. Especificamente no que se refere à Tarifa Social, parece indispensável torná-la de aplicação obrigatória, com critérios definidos de forma consistente e padronizada, instrumentalizando o poder de enforcement das agências reguladoras. Por sua vez, o exercício desse poder de enforcement demanda a estruturação de agências reguladoras revestidas de efetiva capacidade técnica e operacional, em observância daquilo que estabelece a Lei 11.445/2007. A ausência de regulação em diversos municípios indica que ainda há muito o que avançar nessa direção.

\section{REFERÊNCIAS}

ABRANCHES, Sérgio Henrique Hudson de. Reforma regulatória: conceitos, experiências e recomendações. Revista do Serviço Público, v. 50, n. 2, p. 19-50, 1999. Disponível em: http://www.spell.org.br/documentos/ver/35967/reforma-regulatoria--conceitos--experiencias-e-recomendacoes. Acesso em: 30 ago. 2019. ALMEIDA, Aline Paola Correa Braga Câmara de. As tarifas e as demais formas de remuneração do serviço público. Rio de Janeiro: Lúmen Júris, 2009. p. 76.

ARAÚJO, Flávia Camargo; BERTUSSI, Geovana Lorena. Saneamento básico no Brasil: estrutura tarifária e regulação. Planejamento e Políticas Públicas, n. 51, p. 165-202, jul./dez. 2018.

ABAR. Associação Brasileira das Agências de Regulação. Saneamento básico: regulação 2019. Brasília, DF: Abar, 2019. Disponível em: http://abar.org.br/?mdocs-file=57024. Acesso em: 29 abr. 2020.

ABAR. Associação Brasileira de Agências de Regulação. Tarifa social nas companhias estaduais de saneamento básico e o papel da regulação. Brasília, 2018. Disponível em: http://abar.org.br/wp-content/uploads/2018/12/3.-Estudo-Tarifa-Social-ABAR-19-12.pdf. Acesso em: 20 mar. 2019.

BALDWIN, Robert; SCOTT, Colin; HOOD, Christopher. Introduction. In: BALDWIN, Robert; SCOTT, Colin; HOOD, Christopher (org.). A Reader on Regulation. Oxford: Oxford University Press, 1998. p. 1-55.

BRASIL. Decreto n. 7.217, de 21 de junho de 2010. Regulamenta a Lei no 11.445, de 5 de janeiro de 2007, que estabelece diretrizes nacionais para o saneamento básico, e dá outras providências. Diário Oficial da União, Brasília, 22 jun. 2010. Disponível em: http://www.planalto.gov.br/ccivil_03/_Ato2007-2010/2010/ Decreto/D7217.htm. Acesso em: 10 mar. 2019.

BRASIL. Decreto n. 82.587, de 6 de novembro de 1978. Regulamenta a Lei no 6.528, de 11 de maio de 1978, que dispõe sobre as tarifas dos serviços públicos de saneamento e dá outras providências. Diário Oficial da União, Brasília, 7 nov. 1978. Disponível em: https://www2.camara.leg.br/legin/fed/decret/1970-1979/decreto-82587-6-novembro-1978-431846-publicacaooriginal-1-pe.html. Acesso em: 10 mar. 2019. 
BRASIL. Lei no 8.987, de 13 de fevereiro de 1995. Dispõe sobre o regime de concessão e permissão da prestação de serviços públicos previsto no art. 175 da Constituição Federal, e dá outras providências. Brasília, 1995. Disponível em: http://www.planalto.gov.br/ ccivil_03/leis/L8987cons.htm. Acesso em: 7 dez. 2019.

BRASIL. Lei 11.445, de 5 de janeiro de 2007. Estabelece as Diretrizes Nacionais para o Saneamento Básico. Diário Oficial da União, Brasília, 8 jan. 2007. Disponível em: http://www.planalto.gov.br/ccivil_03/_ ato2007-2010/2007/lei/l11445.htm. Acesso em: 10 mar. 2019.

BRASIL. Ministério do Desenvolvimento Regional. Secretaria Nacional de Saneamento Ambiental. Sistema Nacional de Informações sobre Saneamento - SNIS. Brasília: SNSA/MCIDADES, 2018. (Série Histórica). Disponível em: http://app.cidades.gov.br /serieHistorica/. Acesso em: 11 mar. 2020.

BRASIL. Ministério do Desenvolvimento Regional. Secretaria Nacional de Saneamento - SNS. Sistema Nacional de Informações sobre Saneamento: 24 Diagnóstico dos Serviços de Água e Esgotos - 2018. Brasília: SNS/MDR, 2019a. 180 p. Disponível em: http://www.snis.gov.br/downloads/diagnosticos/ae/2018/ Diagnostico_AE2018.pdf. Acesso em: 3 jan. 2020.

BRASIL. Ministério do Desenvolvimento Regional. Secretaria Nacional de Saneamento - SNS. Sistema Nacional de Informações sobre Saneamento: Glossário de Informações - Água e Esgotos 2018. Brasília: SNS/ MDR, 2019b. 74 p. Disponível em: http://www.snis.gov.br/diagnostico-anual-agua-e-esgotos/diagnostico-dos-servicos-de-agua-e-esgotos-2018. Acesso em: 3 jan. 2020.

BRASIL. Plano Nacional de Saneamento Básico: Plansab. Brasília: Ministério das Cidades, 2013. Disponível em: http://www.cidades.gov.br/images/stories/Arquivos SNSA/Arquivos_PDF/plansab_06-12-2013.pdf. Acesso em: 15 mar. 2019.

BRITTO, Ana Lúcia. Panorama do saneamento básico no Brasil - avaliação político-institucional do setor de saneamento básico. Volume IV. Ministério das Cidades. Secretaria Nacional de Saneamento Ambiental, 2011. Disponível em: http://bibliotecadigital.seplan.planejamento.gov.br/bitstream/handle/iditem/271/ PANORAMA_Vol_4.pdf?sequence=4. Acesso em: 15 fev. 2020.

CEPAL. Comisión Económica Para América Latina y el Caribe. La ineficiencia de la desigualdad. Síntesis (LC/ SES.37/4), Santiago, 2018. Disponível em: https://repositorio.cepal.org/bitstream/handle/11362/43566/ S1800302_es.pdf?sequence=4\&isAllowed=y. Acesso em: 10 jan. 2020.

CRUZ, Karlos Arcanjo da; RAMOS, Francisco de Sousa. Evidências de subsídio cruzado no setor de saneamento básico nacional e suas consequências. Nova Econ., Belo Horizonte, v. 26, n. 2, p. 623-651, ago. 2016. Disponível em: http://www.scielo.br/s cielo.php?script=sci_arttext\&pid=S0103-63512016000200623\&lng=en\&nrm=iso. Acesso em: 13 abr. 2019.

GASPARINI, Diógenes. Direito administrativo. 15. ed. São Paulo: Saraiva, 2010.

GALVÃO JÚNIOR, Alceu de Castro; PAGANINI, W. Aspectos conceituais da regulação dos serviços de água e esgoto no Brasil. Eng. Sanit. Ambient., Rio de Janeiro, v. 14, n. 1, p. 79-88, 2009. Disponível em: http:// www.scielo.br/scielo.php?script=sci_arttext\&pid=S1413-41522009000100009\&lng=en\&nrm=iso. Acesso em: 5 mar. 2019.

JORDANA, Jacint; LEVI-FAUR, David. The politics of regulation in the age of governance. In: JORDANA, Jacint; LEVI-FAUR, David. The politics of regulation: institutions and regulatory reforms for the age of governance. Northampton, MA: Edward Elgar, 2004. Disponível em: https:/eclass.uoa.gr/modules/document/ file.php/PSPA 108/regulation.pdf. Acesso em: 10 set. 2019.

JORDANA, Jacint; LEVI-FAUR, Davi; MARÍN, Xavier Fernández. The global diffusion of regulary agencies: channels of transfer and stages of diffusion. Comparative Political Studies, n. 1.343, 2011. Disponível em: https://www.ibei.org/the-global-diffusion-of-regulatory-agencies-channels-of-transfer-and-stages-of-diffusion_20644.pdf. Acesso em: 13 ago. 2019.

JOSÉ, Fábio; MORAES, Francisca Cândida Candeias; HOLLNAGEL, Heloisa Candia Hollnage. Políticas públicas de saneamento básico no Estado de São Paulo. Revista Internacional de Debates da Administração Pública, São Paulo, v. 3, n. 1, p. 104-121, jan./dez. 2018.

JOURAVLEV, Andrei. Regulación de la industria de agua potable: regulación de las conductas. Santiago do Chile: Cepal, 2001. v. 2. Disponível em: https://repositorio.cepal.org/bitstream/handle/11362/6393/1/ S01121097_es.pdf. Acesso em: 2 nov. 2019.

MARQUES, Eduardo Cesar. Condições habitacionais e urbanas no Brasil. In: ARRETCHE, Marta (org.). Trajetórias das desigualdades: como o Brasil mudou nos últimos cinqüenta anos. São Paulo: Editora Unesp, 2015.

MARQUES NETO, Floriano de Azevedo. Agências reguladoras independentes: fundamentos e seu regime jurídico. Belo Horizonte: Fórum, 2009a. 
MARQUES NETO, Floriano de Azevedo. A regulação no setor de saneamento. In: CORDEIRO, Berenice de Souza (coord.). Instrumentos das políticas e da gestão dos serviços públicos de saneamento básico. Livro I (Coletânea). Brasília: Editora, 2009b. Disponível em: https://web.bndes.gov.br/bib/jspui/bitstream/1408/2161/2/Lei\%20nacional\%20de\%20saneamento\%20basico_Livro\%20I_P_BD.pdf. Acesso em: 13 jan. 2020.

MEIRELLES, Dimária Silva e. Teorias de mercado e regulação: por que os mercados e o governo falham? Cad. EBAPE.BR, Rio de Janeiro, v. 8, n. 4, p. 644-660, dez. 2010. Disponível em: http://www.scielo.br/scielo.php?script=sci_arttext\&pid=S1679-39512010000400006. Acesso em: 15 nov. 2019.

MINOGUE, Martin. Governance-Based Analysis of Regulation. Annals of Public and Cooperative Economics, v. 73, p. 649-666, 2002. Disponível em: https://onlinelibrary.wiley.com/doi/epdf/10.1111/14678292.00209. Acesso em: 28 mar. 2019.

MOREIRA, Juarez Nazareno Muniz. Custos e preços como estratégia gerencial numa empresa de saneamento. 1998. Dissertação (Mestrado em Engenharia de Produção) - Universidade Federal de Santa Catarina, Florianópolis, 1998. Disponível em: https://repositorio.ufsc.br/xmlui/handle/123456789/77484. Acesso em: 22 mar. 2019.

NASCIMENTO, Carlo Bruno Lopes. Dificuldades de regulação econômica: uma leitura das teorias de regulação. RJLB, ano 1, n. 4, p. 191-238, 2015.

OLIVEIRA, Robson Rocha. Dos conceitos de regulação às suas possibilidades. Saúde Soc., São Paulo, v. 23, n. 4, p. 1.198-1.208, 2014.

ONU. Organização das Nações Unidas. Resolução A/RES/64/292. 28 jul. 2010a. Disponível em: http:// www.un.org/en/ga/search/view_doc.asp?symbol=A/RES/64/292. Acesso em: 5 abr. 2019.

ONU. Organização das Nações Unidas. Resolução 15/9. Conselho de Direitos Humanos, Human rights and access to safe drinking water and sanitation. Doc. a/hrc/res/15/9, Genebra, 30 set. 2010b. Disponível em: https://www.un.org/ga/search/vi ew_doc.asp?symbol=A/HRC/RES/15/9\&Lang=E. Acesso em: 4 abr. 2019.

PEIXOTO; João Batista. Aspectos da gestão econômico-financeira dos serviços de saneamento básico no Brasil. In: HELLER, Léo, CASTRO, José Esteban (org.). Política pública e gestão de serviços de saneamento. Belo Horizonte: Editora UFMG, 2013.

PINDYCK, Robert Stephen; RUBINFELD, Daniel Lee. Microeconomia. 6. ed. São Paulo: Pearson Prentice Hal, 2006.

PIRES, José Cláudio Linhares; PICCININI, Maurício Serrão. A regulação dos setores de infraestrutura no Brasil. In: GIAMBIAGI, F.; MOREIRA, M. (org.). A economia brasileira nos anos 90. Rio de Janeiro: BNDES, 1999. Disponível em: https://web.bndes.gov.br/bib/jspui/bitstream/1408/11578/3/A\%20Economia\%20 Brasileira\%20nos\%20Anos\%2090_A\%20Regula\%C3\%A7\%C3\%A30\%20dos\%20Setores\%20de\%20Infra-estrutura\%20no\%20Brasil_P.pdf. Acesso em: 22 mar. 2019.

SALGADO, Lúcia Helena; MOTTA, Ronaldo Seroa da. Marcos Regulatórios no Brasil: o que foi feito e o que falta fazer. Rio de Janeiro: Ipea, 2005. Disponível em: http://www.ipea.gov.br/portal/images/stories/ PDFs/livros/marcosRegulatoriosNoBrasil-11.pdf. Acesso em: 28 mar. 2019.

SANTOS, Gesmar Rosa; KUWAJIMA, Julio Issao; SANTANA, Adrielli Santos de. Regulação e investimento no setor de saneamento no Brasil: trajetórias, desafios e incertezas. Texto para Discussão 2587. Rio de Janeiro: Ipea, 2020.

SILVEIRA, Ana Carolina Gava Lima. Os efeitos da polêmica dos reajustes de 2003 sobre o valor das empresas de telefonia fixa na Bovespa. 2006. 125 f. Dissertação (Mestrado em Administração) - Pontifícia Universidade Católica, Rio de Janeiro, 2006. Disponível em: https://www.maxwell.vrac.puc-rio. br/9878/9878_1.PDF. Acesso em: 10 fev. 2019.

TRATA BRASIL. Saneamento básico: uma agenda regulatória e institucional. 2018. 56 p. Disponível em: http://www.tratabrasil.org.br/uploads/saneamento-basico-web.pdf. Acesso em: 10 mar. 2019.

TRINDADE, Adriano Drummond Cançado. A teoria da regulação econômica aplicada ao setor mineral brasileiro. Revista de Direito Setorial e Regulatório, vol. 5, n. 2, p. 53-78, 2019.

WINDHOLZ, Eric; HODGE, Graeme A. Conceituando regulação social e econômica: implicações para agentes reguladores e para a atividade regulatória atual. Revista de Direito Administrativo, v. 264, p. 13-56, 2013. Disponível em: http://bibliotecadigital.fgv.br/ojs/index.php/rda/article/view/14076. Acesso em: 15 mar. 2019. 